\title{
PERFORMANCE OF VARIABLE-ORIFICE NOZZLES FOR LIQUID FERTILIZER APPLICATIONS
}

\author{
A. Sharda, J. P. Fulton, R. K. Taylor
}

\begin{abstract}
Variable-rate application continues to gain interest among precision agriculture practitioners including the use of crop sensor technology for application of nitrogen in grain crops. For liquid fertilizers, variable-orifice nozzles are being implemented since they provide a much larger nozzle flow range compared to traditional fixed orifice nozzles. However, understanding the performance of variable-orifice nozzles under different field operating conditions has been limited. Therefore, the objective of this study was to evaluate the performance of variable orifice nozzles in support of variable-rate application. Two common variable-orifice nozzles offered by different companies were selected for this study. They were tested over three flow ranges $(0.76$ to $1.89 \mathrm{~L} / \mathrm{min})$ with all tests replicated three times. A commercially available 18.6-m, wet boom sprayer equipped with 37 nozzle bodies was used. Nozzles were numbered but then randomly assigned a position along the boom. To evaluate the performance of an individual nozzle, three random nozzle locations along the spray boom were established for both sets of nozzles. Therefore, 18 tests per replication were required to include the 3 flow rates, 3 different locations, and 2 nozzle types. Once the desired flow rate test was established, tip flow was measured using SpotOn Sprayer Calibrator technology. Tip flows were recorded and statistical analyses performed to evaluate flow uniformity (CV) across the boom but also detect off-rate errors by individual nozzles and locations across the boom. With the exception of a few nozzles, the uniformity across the spray boom, as defined by the $C V$, was acceptable for both nozzle types over approximately a 2:1 flow range. Both nozzle types were less uniform at the low flow rate. There were three nozzles of each type that resulted in unacceptable flow errors in multiple tests.
\end{abstract}

Keywords. Precision agriculture, Sprayer, Nozzles, uniformity, Variable rate.

A doption of precision agriculture technologies and practices has improved overall production efficiency and increased corn and soybean yields (USDA-ERS, 2011). Precision agriculture has also improved management decisions through the use of maps and other data layers while reducing environmental risks. One aspect that precision agriculture technology addresses is the over-application of fertilizers through the use of variable-rate technology (VRT) allowing producers to account for sub-field nutrient variability and automatic section control eliminating $2 \mathrm{X}$ or $3 \mathrm{X}$ application in areas previously applied. The use of crop sensors has garnered attention of producers for nitrogen management by applying rates based on crop health or needs during mid-season application. With regulations and need to better manage input costs at the farm level, producers are evaluating methods to improve the

Submitted for review in July 2015 as manuscript number MS 11428; approved for publication by the Machinery Systems Community of ASABE in January 2015.

The authors are Ajay Sharda, ASABE Member, Assistant Professor, Kansas State University, Manhattan, Kansas; John P. Fulton, ASABE Member, Associate Professor, Food, Agriculture and Biological Engineering Department, The Ohio State University, Columbus, Ohio; Randal K. Taylor, ASABE Member, Professor, Department of Biosystems Engineering, Oklahoma State University, Stillwater, Oklahoma. Corresponding author: Ajay Sharda, Kansas State University, Seaton Hall 140, Manhattan, KS 66506; phone: 785-532-2936; e-mail: asharda@ksu.edu. management of nitrogen and phosphorus with precision agriculture technology providing an option.

Variable-rate application (VRA) of inputs continues to grow among precision agriculture practitioners with fertilizer and seed being two popular inputs to vary. Adopters of variable-rate fertilization have indicated higher yields for corn and soybeans (USDA-ERS, 2011). VRA of nitrogen (VRN) in corn has demonstrated profitability a majority of the time (Bullock, 2009). In some cases, VRN has shown a reduction of total $\mathrm{N}$ applied and can be more economically feasible over uniformly applied $\mathrm{N}$ (Koch et al., 2004). Additional considerations for VRN include the resolution at which it should be implemented to account for actual crop variability, ability to improve nitrogen use efficiency (NUE), thereby reducing total amount applied without yield loss, and capabilities to apply over the wide range of traditional application rates given crop needs. While profitability or the economic optimum nitrogen rate (ENOR; Scharf et al., 2006) must be considered for each of the three points, the price of precision agriculture technology continues to decline while data generation on a field basis increases allowing producers to consider and implement VRN strategies in a cost effective manner while receiving both economic and environmental benefits. Raun et al. (2002) indicated that $1 \mathrm{~m}^{2}$ in wheat should be sensed and managed independently under a VRN strategy using crop sensors and that at this resolution NUE improved by $>15 \%$. As an example, their average top-dress $\mathrm{N}$ ratio ranged by $2.5: 1$ with no preplant applied $\mathrm{N}$ but this ratio 
increased by almost a factor of four when $45 \mathrm{~kg} \mathrm{~N} \mathrm{ha}^{-1}$ was applied preplant. This factor ignores one location where the minimum $\mathrm{N}$ rate was $0.02 \mathrm{~kg} \mathrm{ha}^{-1}$. These ratios can be similar for VRN, mid-season application of corn where rates could range from 0 to $374 \mathrm{~L} \mathrm{ha}^{-1}$. Therefore, the capabilities of the application technology and nozzle must nominally meet the range of expected $\mathrm{N}$ rates in order to maximize the benefit of VRN.

Given the potential range in prescribed or expected target rates under a VRN strategy, standard fixed orifice nozzles are unable to apply the desired rates for liquid $\mathrm{N}$ products such as urea-ammonium nitrate (UAN) commonly used during mid-season application. Most fixed orifice nozzles used for liquid fertilizer are limited to a 1.8 or less turndown ratio indicating that over the recommended operating pressure they are unable to double (turndown ratio $=2$ ) the application rate. Flow through a fixed orifice nozzle is proportional to the square root of pressure; thereby pressure must quadruple to double the flow rate. Researchers have explored options to increase the range in application rates for liquid products. Giles and Comino (1990) developed a spray rate control system providing a turndown ratio between 2.5 and 3.5:1 using different fixed orifice nozzles. They obtained this turndown ratio through the use of pulse-width modulation (PWM), varying the frequency and duty cycle of a solenoid valve installed at the nozzle body. Bui (2005) outlined a variable orifice nozzle offering flow in the range of 0.57 to $3.03 \mathrm{~L} \mathrm{~min}^{-1}$ (turndown ratio $=5.3$ ) between the pressure of 103 to $345 \mathrm{kPa}$, respectively. Daggupati (2007) studied droplet sizes from varitarget nozzles during tests conducted at varying speed (4 to $12 \mathrm{mph}$ ) and application rate (4 to 12 GPA) and reported that droplet size varied from little (456 to 621 microns) which could potentially provide efficient application. Similar results on droplet spectra and spray pattern were observed by Luck et al., (2015). Most commercially available variable orifice nozzles provide flow directly proportional to the change in pressure (Dilawari et al., 2008). For liquid VRN, most producers or custom applicators will select variable-orifice nozzles in order to better accommodate the expected $\mathrm{N}$ rates during field application. However, the performance of variableorifice nozzles has not been documented to understand lateral uniformity or potential off-rate errors during the application of liquid products. Therefore, the objective of this study was to evaluate the performance of two commercially available variable-orifice nozzles in terms of consistency among nozzles and repeatability of individual nozzles with respect to flow rate.

\section{METHODS}

Two styles of variable orifice nozzles (fig. 1) were used for this study: TurboDrop ${ }^{\circledR}$ Variable Rate (TD) (GreenLeaf Technologies; Covington, La.) and VariTarget (VT) yellow tip (SprayTarget; Rosemount, Minn.). A pull-type sprayer with 37 nozzles mounted across an 18.6-m boom was used to evaluate the nozzle combinations (fig. 2). The sprayer was plumbed into three boom sections and equipped with a

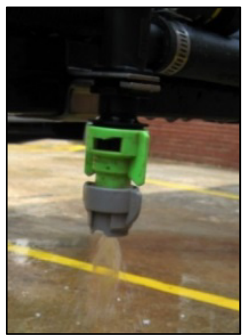

(a)

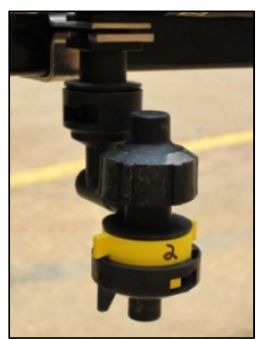

(b)
Figure 1. Illustration of the TurboDrop ${ }^{\circledR}$ Variable Rate (a) and VariTarget (b) nozzles used in this study.

Raven Viper rate controller (Raven Industries, Sioux Falls, S. Dak.). The sprayer was instrumented with thin film pressure transducers (Model 1502 B81 EZ 100 PSI G, PCB Piezotronics Inc., Depew, N.Y.) to measure nozzle and system pressure and; an inline flow meter (Model FT-16NEXW-LEG-5, Flow Technology Inc., Tempe, Ariz.) to record overall system flow rate. Pressure transducers were mounted at the boom manifold, and three randomly selected nozzle locations 4,17 , and 32 along the spray boom. The flow meter was installed downstream of the flow-regulating valve. Measurement accuracy of the pressure transducers was $<0.25 \%$ full scale with a response time of $<1 \mathrm{~ms}$ for a 0 to $689.5 \mathrm{kPa}$ measurement range. Flow meter accuracy was $\pm 0.05 \%$ full scale with 3 to $4 \mathrm{~ms}$ response time over a 0 to $227 \mathrm{~L} \mathrm{~min}^{-1}$ measurement range.

A set of 37 TDVR-015 (fig. 1a) and VT-yellow tip nozzles (fig. 1b) were selected. Each nozzle within the two types was labeled with an identification number (ID) from 1 through 37 (fig. 2). Microsoft Excel was used to randomly assign a nozzle ID to boom-section location thus generating three different nozzle ID configurations on the boom-section. This randomization ensured each nozzle was installed at three unique boom-section locations. The nozzle ID to boom-section location assignment for the three configurations was the same for both nozzle types. Prior to each test, the rate controller was programmed to apply water at one of the three application rates noted as low, medium or high (table 1). For the TD nozzle, the spray system pressure reached $655 \mathrm{kPa}$ at $1.51 \mathrm{~L} \mathrm{~min}^{-1}$ nozzle flow rate, which was considered excessive for the spray application system. Therefore, high flow rate tests for the TD nozzle were conducted at $1.51 \mathrm{~L} \mathrm{~min}^{-1}$ nozzle flow rate and at $1.89 \mathrm{~L} \mathrm{~min}^{-1}$ for the VT nozzle. Overall, 54 tests were conducted; 2 nozzle types, 3 flow rates, 3 nozzle mounting configurations, replicated 3 times.

For each test, nozzles were mounted in a selected configuration with desired nozzle ID at the specified boomsection location. The rate controller was programmed to achieve the target flow rate (table 1). The sprayer was operated for $60 \mathrm{~s}$ to attain stable nozzle flow conditions before data collection commenced. Subsequently, the flow rate from each nozzle was measured (fig. 3) using SpotOn Sprayer Calibrator s (Model SC-1, Innoquest Inc., Woodstick, Ill.) with an accuracy of $\pm 2.5 \%$. National Instruments CompactRIO ${ }^{\mathrm{TM}}$ utilized cRIO-9014controller, cRIO-9103 chassis and NI $9221 \mathrm{C}$ series analog modules system to measure system pressure, nozzle pressure and 


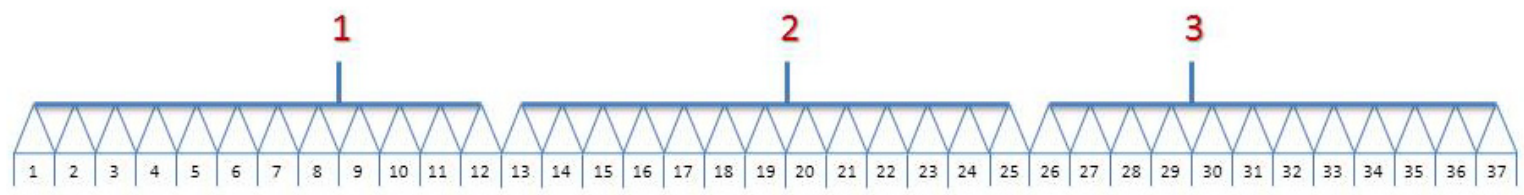

12

13

12

\section{\# of Nozzles per sub-section}

Figure 2. Sprayer plumbing diagram by section and the T-connection at each boom-section. Nozzle locations (1-37) and boom-sections $(1,2$, or 3) were numbered from left to right on the sprayer.

overall system flow rate using a program written in LabVIEW version 2009. The LabVIEW program logged data at $20 \mathrm{~Hz}$ while time stamping all data.

To test the consistency and repeatability of the nozzles at different pressures, relative flow for each nozzle across each pressure and CV (eq. 1) was calculated. Analysis of variance was performed in SAS 9.1 (SAS, Cary, N.C.) using PROC ANOVA to detect relative flow differences among nozzles. Data for each nozzle was analyzed by nozzles to test the consistency and by pressure to test for repeatability of nozzles. Means were separated using the least significant difference (LSD) option at a 0.01 level of significance.

$$
C V=\frac{S D^{* 100}}{\text { Mean }}
$$

where

$\mathrm{CV}=$ Coefficient of Variation in nozzle flow,

$\mathrm{SD}=$ Standard deviation in different nozzles flow rate (L/min),

Mean $=$ Mean of nozzle flow rate across nozzles $(\mathrm{L} / \mathrm{min})$.

\section{RESUlTS AND DISCUSSION}

The relative flow data were first analyzed by boom position. The data from both nozzles and all flows were combined for a total of 54 observations at each position. While there were significant flow differences across the boom, the relative flow was within $6 \%$ for all positions. Nozzle at boom-section locations adjacent to the inlet tee averaged $2 \%$ higher flow and nozzles at the end of each boom section averaged 1\% lower flow. Aside from that, there were no consistent observations related to nozzle position on the boom. Thus, the position on the boom was ignored and subsequent analysis focused on the nozzles.

The published pressure/flow curves for the two nozzles tested along with a similar fixed orifice nozzle are shown as lines in figure 4 . The points on figure 4 are the nozzle pressure and flow data measured for the two types of nozzles during this study. A regression line was fitted on

Table 1. Nominal low, medium, and high flow rates used for VT and TDVR nozzles.

\begin{tabular}{|c|c|c|}
\hline \multirow[b]{2}{*}{ Nozzle Flow } & \multicolumn{2}{|c|}{ Flow Rate $\left(\mathrm{L} \mathrm{min}^{-1}\right)$} \\
\hline & VT & TD \\
\hline$\overline{\text { Low }}$ & & \\
\hline Medium & & \\
\hline High & 1.89 & 1.51 \\
\hline
\end{tabular}

data for both the nozzle types. The VT nozzle performed (fig. 4) as advertised by the manufacturer. The TD nozzle followed a trend similar to the fixed-orifice tip curve. Both the regression curves suggested the nozzles flow rate followed trends similar to the manufacturer's specifications; however there were slight deviation in flow rate at low application pressure. There was greater flow rate deviation at lower application pressures for TD nozzles and it was primarily because it was lower than the manufacturer recommended lower pressure range of $275 \mathrm{kPa}$. While the measured data for the nozzles deviates from the manufacturers' curve, the characteristics are similar. Additionally the variability at a given pressure is the variation in nozzle flow across the boom. The mean flow rates across the boom were within $5 \%$ of the target flow rate. The summary statistics for each treatment are shown in table 2. The data in each row are the summary of nine tests (three nozzle locations on the boom $\times$ three replications). The CVs across the boom for all tests were $10 \%$ or less. The CVs for the VT nozzles were similar across all flow rates while those for the TD tended to decrease with increasing flow rates. The CV for the TD nozzles at the lowest flow rate was similar to those for the VT. However the TD nozzles were more uniform than the VT at higher flow rates. It should be noted that we were

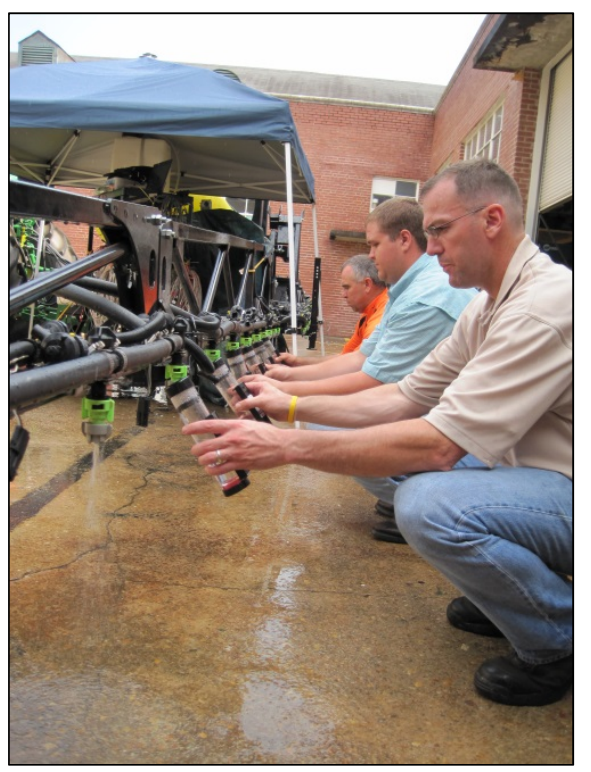

Figure 3. Nozzle flow rate measurement using SpotOn Sprayer Calibrator. 


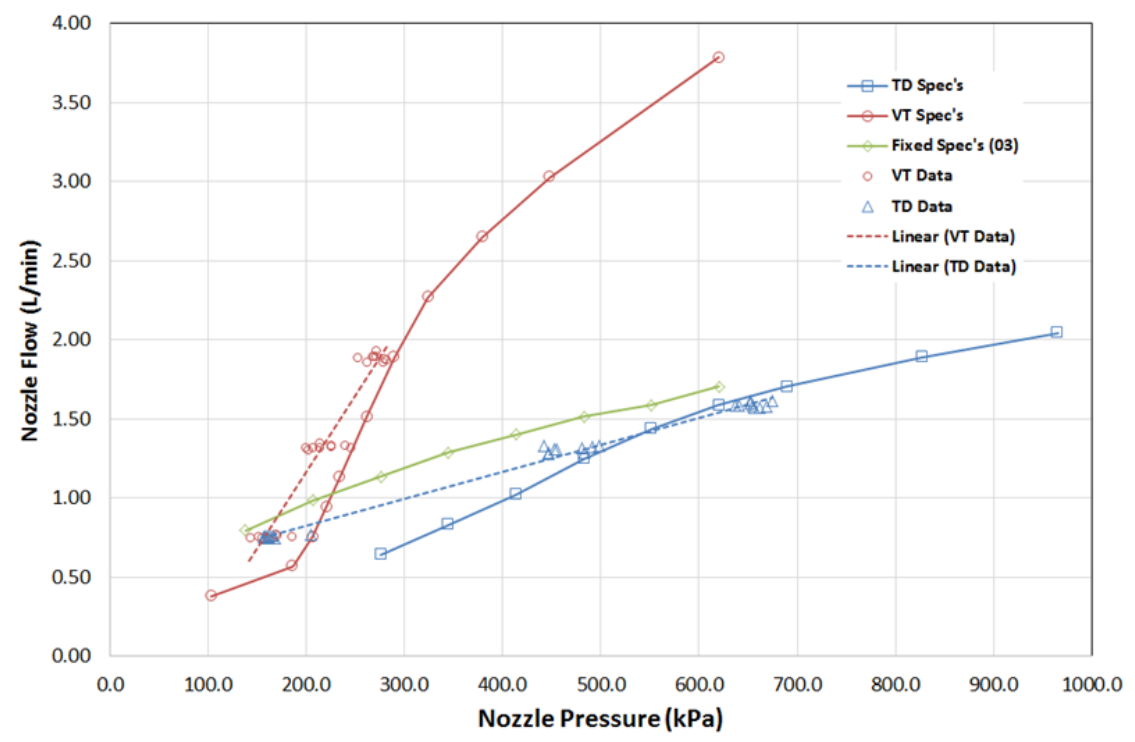

Figure 4. Published pressure-flow characteristics for both nozzles and a similar fixed orifice tip (03) along with the mean nozzle pressure and flow data collected during this study.

unable to achieve the highest target flow rate with the TD nozzles without exceeding the pressure limits of the system. While the CVs indicate a fairly uniform application, the range in flow may seem high for all tests. The mean and maximum flow rates for the two nozzles were similar, with the exception of the aforementioned high rate for the TD. However the minimum flow rates for the VT were consistently lower than the TD creating greater ranges indicating that the data are negatively skewed. The histograms for the nozzle/flow combinations are shown in figure 5. The VT nozzle at the high target flow illustrates this negative skewness.

Across the boom uniformity as defined by the $\mathrm{CV}$ is one method to assess uniformity. ASABE Standards (2011) state that nozzles that deviate more than $10 \%$ from the boom mean should be replaced. Similar recommendations are provided in ISO 16122-2 (2015). At the low target flow rate there were seven TD nozzles that had flow rates outside of this $10 \%$ range (table 3 ). There were three TD nozzles with high flow rates for the medium target flow with two of these three also exhibiting high flow rates at the highest target flow. There were no TD nozzles with low flow rates at the medium and high target flows. Overall, there were 12 instances where TD nozzles performed outside of the $10 \%$ range, but it occurred with only seven unique nozzles. The TD nozzles were most likely to err on over application. Two nozzles over applied in all flow tests and one nozzle over applied in two flow tests. Since the rate controller works to keep the set rate at the boom, the tendency of these nozzles to over apply resulted in a slight under application across the rest of the boom. This is shown in table 3 where the median flow for the TD nozzle is consistently less than the mean flow.

At the low target flow rate there were seven VT nozzles that had flow rates outside of the $10 \%$ range. Five nozzles had excessively high flow rates and two had low flow rates. One of the five VT nozzles in the excessively high group had a high flow rate for the medium target flow and none were high at the highest flow rate. While two nozzles had excessively low flows at the medium target flow, neither were low in the low target flow rate tests. However, these two VT nozzles and one other nozzle had excessively low flow rates for the high target flow tests. There were 13 occurrences of misapplication with the VT nozzles, but these happened with only 10 nozzles. One VT nozzle over applied in two flow tests and two nozzles under applied in two flow tests. In general, the VT nozzles over applied during the low flow test and under application for the high flow tests.

\section{Conclusions}

While there were some significant flow rate differences among the nozzle positions on the boom, there were no consistent application errors exceeding six percent at any nozzle position. Furthermore, the differences could not be attributed to boom plumbing connections. Since each nozzle was only placed in three different boom-section locations, the differences were attributed to nozzles. With

Table 2. Boom performance summary statistics for the two nozzles across all tests. ${ }^{[a]}$

\begin{tabular}{|c|c|c|c|c|c|c|c|c|c|c|}
\hline Nozzle & Flow & Target & Mean & Median & Min & Max & Range & Std. Dev & CV (\%) & Skewness \\
\hline TD & High & 1.514 & 1.590 & 1.565 & 1.022 & 1.930 & 0.908 & 0.102 & 6.39 & 0.30 \\
\hline TD & Med & 1.325 & 1.308 & 1.279 & 0.871 & 1.628 & 0.757 & 0.099 & 7.60 & 0.29 \\
\hline TD & Low & 0.757 & 0.757 & 0.751 & 0.454 & 0.984 & 0.530 & 0.073 & 9.65 & -0.07 \\
\hline VT & High & 1.893 & 1.891 & 1.904 & 0.719 & 2.233 & 1.514 & 0.183 & 9.69 & -2.36 \\
\hline VT & Med & 1.325 & 1.329 & 1.344 & 0.643 & 1.628 & 0.984 & 0.122 & 9.19 & -1.70 \\
\hline VT & Low & 0.757 & 0.759 & 0.772 & 0.416 & 0.984 & 0.568 & 0.076 & 10.03 & -0.59 \\
\hline
\end{tabular}

[a] Each test is the combination of three repetitions. Units are $\mathrm{L} \mathrm{min}^{-1}$. 


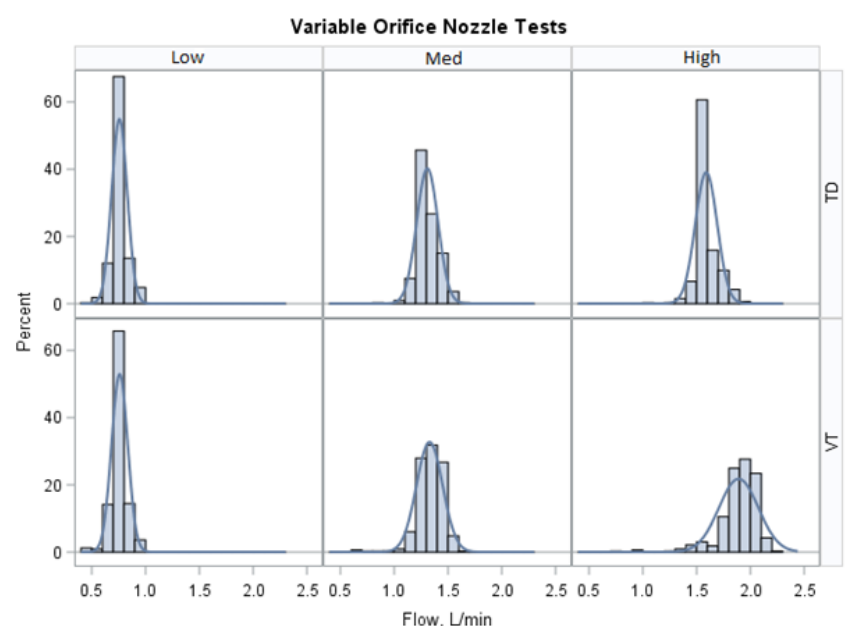

Figure 5. Histograms and normal distribution curves for the nozzle/flow combinations.

the exception of a few nozzles, the uniformity across the spray boom, as defined by the $\mathrm{CV}$, was acceptable for both nozzle types over approximately a 2:1 flow range. The regression curves fitted to data for both nozzles suggested the nozzles flow rate followed trends similar to the manufacturer's specifications; however there were slight deviation in flow rate at low application pressure. Both nozzle types were less uniform at the low flow rate. This result at low flow could certainly be problematic during a variable-rate nitrogen (VRN) application as a lower application rate would call for lower flow. The nonuniform application at low rates could cause streaking in the crop. Therefore, users might select nozzles with target flow rate to be in the middle of flow range of selected variable rate nozzle. There were three nozzles of each type that resulted in unacceptable flow errors in multiple tests. These nozzles would likely be identified during a thorough calibration. In general, the TD nozzles with unacceptable flow caused the rest of the boom to operate at a flow below the intended rate. The median flow for the VT nozzles was generally greater than the mean indicating that more of the boom was operating above the average flow rate.

\section{REFERENCES}

ASABE Standards. (2011). S592: Best management practices for boom spraying. St. Joseph, MI: ASABE.

Bui, Q. D. (2005). VariTarget- A new nozzle with variable flow rate and droplet optimization. ASABE Paper No. 051125. St. Joseph, MI: ASABE

Table 3. Coefficient of variation for each of 37 nozzles for brands TD and VJ based on nine independent tests for each nozzle. ${ }^{[a]}$

\begin{tabular}{|c|c|c|c|c|c|c|c|}
\hline \multicolumn{4}{|c|}{ TD } & \multicolumn{4}{|c|}{ VT } \\
\hline ID & Low & Medium & High & ID & Low & Medium & High \\
\hline 1 & 7.13 & 4.25 & 3.04 & 1 & 2.12 & 2.50 & 2.35 \\
\hline 2 & 3.42 & 3.50 & 2.59 & 2 & 1.58 & 1.93 & 3.55 \\
\hline 3 & 6.69 & 3.42 & 2.47 & 3 & 3.24 & 4.41 & 2.64 \\
\hline 4 & 3.55 & 3.55 & 2.50 & 4 & 2.73 & 2.55 & 4.06 \\
\hline 5 & 2.17 & 3.95 & 3.97 & 5 & 2.50 & 2.56 & 3.92 \\
\hline 6 & 5.17 & 4.98 & 2.42 & 6 & 4.57 & 4.78 & 5.46 \\
\hline 7 & 5.86 & 3.95 & 4.42 & 7 & 2.54 & 2.76 & 0.99 \\
\hline 8 & 2.23 & 3.09 & 1.87 & 8 & 27.12 & 21.58 & 28.34 \\
\hline 9 & 2.23 & 2.10 & 1.74 & 9 & 4.19 & 5.20 & 5.06 \\
\hline 10 & 6.44 & 5.81 & 2.92 & 10 & 2.42 & 3.62 & 6.96 \\
\hline 11 & 8.04 & 7.11 & 7.02 & 11 & 4.32 & 4.74 & 2.42 \\
\hline 12 & 6.18 & 5.11 & 3.25 & 12 & 2.71 & 2.86 & 5.15 \\
\hline 13 & 8.32 & 6.12 & 2.64 & 13 & 5.33 & 2.43 & 4.11 \\
\hline 14 & 1.76 & 3.62 & 1.63 & 14 & 2.88 & 2.78 & 2.33 \\
\hline 15 & 6.31 & 5.00 & 5.40 & 15 & 2.56 & 10.15 & 5.15 \\
\hline 16 & 6.57 & 6.15 & 4.31 & 16 & 2.99 & 5.14 & 3.92 \\
\hline 17 & 5.78 & 5.42 & 1.87 & 17 & 2.18 & 2.85 & 6.87 \\
\hline 18 & 5.26 & 3.10 & 1.18 & 18 & 12.12 & 16.29 & 12.09 \\
\hline 19 & 12.16 & 9.33 & 7.66 & 19 & 3.14 & 2.77 & 1.33 \\
\hline 20 & 5.50 & 3.76 & 3.12 & 20 & 3.24 & 20.08 & 1.64 \\
\hline 21 & 3.14 & 2.51 & 2.63 & 21 & 2.54 & 2.49 & 2.29 \\
\hline 22 & 11.86 & 4.39 & 4.19 & 22 & 3.21 & 4.82 & 2.07 \\
\hline 23 & 2.99 & 3.51 & 2.44 & 23 & 3.53 & 1.62 & 9.77 \\
\hline 24 & 19.97 & 9.74 & 7.93 & 24 & 15.23 & 15.48 & 19.08 \\
\hline 25 & 1.68 & 2.50 & 1.24 & 25 & 2.59 & 1.76 & 3.73 \\
\hline 26 & 5.53 & 3.70 & 5.24 & 26 & 2.59 & 3.03 & 2.44 \\
\hline 27 & 4.54 & 3.42 & 1.62 & 27 & 1.66 & 2.57 & 3.65 \\
\hline 28 & 3.54 & 2.66 & 1.68 & 28 & 5.00 & 3.79 & 4.24 \\
\hline 29 & 5.78 & 4.86 & 2.08 & 29 & 9.20 & 6.06 & 6.16 \\
\hline 30 & 3.66 & 4.12 & 2.12 & 30 & 2.24 & 2.89 & 2.45 \\
\hline 31 & 3.54 & 2.91 & 1.91 & 31 & 10.62 & 12.86 & 13.07 \\
\hline 32 & 3.89 & 4.26 & 3.19 & 32 & 2.85 & 2.86 & 3.83 \\
\hline 33 & 10.59 & 7.51 & 1.74 & 33 & 2.58 & 2.83 & 8.22 \\
\hline 34 & 3.66 & 4.03 & 3.42 & 34 & 2.50 & 1.96 & 6.63 \\
\hline 35 & 13.14 & 13.55 & 14.32 & 35 & 6.85 & 10.71 & 3.25 \\
\hline 36 & 4.91 & 3.48 & 2.84 & 36 & 8.72 & 3.51 & 6.35 \\
\hline 37 & 7.71 & 7.18 & 3.64 & 37 & 10.36 & 5.19 & 7.25 \\
\hline \multicolumn{8}{|c|}{$\%$ of Nozzles with a $\mathrm{CV} \geq 10$ Based on 9 Independent Tests } \\
\hline & 14 & 3 & 3 & & 14 & 19 & 11 \\
\hline
\end{tabular}

[a] Nozzles are listed in order with highlighted cells having a $\mathrm{CV} \geq 10.00 \%$. 
Bullock, D. S., Ruffo, M. L., Bullock, D. G., \& Bollero, G. A. (2009). The value of variable rate technology: An informationtheoretic approach. American J. Agric. Economics, 91(1), 209223. http://dx.doi.org/10.1111/j.1467-8276.2008.01157.x

Daggupati, N. P. (2007). Assessment of the VariTarget nozzle for variable rate application of liquid crop protection products. MS thesis. Manhattan, KS: Kansas State University, Department of Biological and Agricultural Engineering.

Dilawari, G., Taylor, R. K., Solie, J. B., \& Bennur, P. (2008). Nozzles for variable rate fertilizer application. ASABE Paper No. 083732. St. Joseph, MI: ASABE.

Giles, D. K., \& Comino, J. A. (1990). Droplet size and spray pattern characteristics of an electronic flow controller for spray nozzles. J. Agric. Eng. Res., 47, 249-267. http://dx.doi.org/10.1016/00218634(90)80045-V

ISO. (2015). 16122-2. Agricultural and forestry machinery: Inspection of sprayers in use-Part 2: Horizontal boom sprayer. Geneva, Switzerland: ISO.
Koch, B., Khosla, R., Frasier, W. M., Westfall, D. G., \& Inman, D. (2004). Economic feasibility of variable-rate nitrogen application utilizing site-specific management zones. Agron. J., 96(6), 1572-1580. http://dx.doi.org/10.2134/agronj2004.1572

Luck, J. D., Pitla, S. K., Sama, M. P., \& Scott, A. S. (2015). Flow, spray pattern, and droplet spectra characteristics of an electronically actuated variable-orifice nozzle. Trans. ASABE, 58(2), 261-269. http://dx.doi.org/10.13031/trans.58.10798

Raun, W. R., Solie, J. B., Johnson, G. V., Stone, M. L., Mullen, R. W., Freeman, K. W., ... Lukina, E. V. (2002). Improving nitrogen use efficiency in cereal grain production with optical sensing and variable rate application. Agron. J., 94(4), 815-820. http://dx.doi.org/10.2134/agronj2002.8150

Scharf, P. C., Kitchen, N. R., Sudduth, K. A., \& Davis, J. G. (2006). Spatially variable corn yield is a weak predictor of optimal nitrogen rate. SSSAJ, 70(6), 2154-2160. http://dx.doi.org/10.2136/sssaj2005.0244

USDA-ERS. (2012). On the doorstep of the information age: Recent adoption of precision agriculture. Economic Information Bulletin No. 80, August 2011. Washington, D.C.: USDA. Retrieved from www.ers.usda.gov/media/81195/eib80_1_.pdf 